\title{
Consecrating the Elite: Culturally embedding the financial market in the City of London
}

Crises, economic or otherwise, are the product of change. As French and Leyshon (2010) argue, they signal the demise of past unsustainable conditions and the recalibration towards an equilibrium that is more profitable for society as a whole. In this manner, the 2007 financial crisis was an opportunity to challenge the power of capital and a dominant market order. It should have been a moment in which the far reaching programme of 'more market' was reversed. Generated interests, ideas and ideologies that operated at the heart of the financial services industry had brought the global economy to the brink of collapse; it was a time to re-couple the unshackled market institutions with regulatory controls of democratic governance. However, opposed to representing a catalyst for change and the re-regulation of market influent in social life, the 2007 financial crisis has presented precisely the opposite. The dominant formation of market power continues to impose a 'taken-for-granted way of life' that exists beyond the scope of contestation or critical discussion. Eight years on and the sobering realisation is that the immediate post-crash clamour for 'change' has not spelt the end of the neoliberal maxim of 'more market'. Rather, the effects of crisis continue to have a profound impact in relation to issues of inequality and social justice throughout society today.

Liberal market societies continue to be a source of recurring crises that have defined the twentieth and early twenty first centuries (Pauly, 2011; Stiglitz, 2010), yet the hegemonic dominance of the market order continues to be represented as a 'pure and perfect order' of political and economic 'truth' (Bourdieu, 2001). It is in this context that this chapter establishes a dominant financial doxa. In short, this represents the 'cultural unconsciousness', or what is taken for granted, of a given social context. Through engrained norms, values and the acceptance of a non-contested version of 'truth', the cultural doxa leads to a shared perception of a version of 'reality' (Bourdieu, 1998; Chopra, 2003). In presenting the market as a form of doxa, this chapter highlights how the dominant institutions of 
political economy establish and perpetuate an embedded cultural 'respect' for the inherent logic of market competition. Rather than existing within some form of 'social essence', the market is viewed as a 'coherent idea' that must be 'realised' and 'sustained' both by the state as well as individual practice (Foucault, 2010). What emerges is a situated and relational version of reality that structures, and is structured by, the impressions on the mind, body and material environment to [re]produce a dominating set of positive (ennobling) or negative (stigmatising) cultural practices. For Bourdieu (1984), this legitimises cultural practice and imposes the norms and realities of the financial experience. Imposing specific forms of struggle, the deep structure of the field of finance and the dominance of the financial markets represents a tacit, fundamental and, crucially, enduring order of the social world. This is, as Swartz (1997) argues, much more powerful than the 'invisible hand' that structures action since it speaks to power relations and the competitive struggle for scarce resources.

Drawing on a three-tiered ethnographic approach, incorporating in-depth interviews, non-participant observation and photographic representation, this three-year study sought to access the individual experiences of City life. Within this, the focus was on establishing an overarching picture through which it is possible to explore a culturally embedded system of situated action and meaning making that produces practice, shapes meaning and constructs social structures. The research focused on gaining access to public sites of social interaction whilst purposively targeting front office economic actors, including traders, investment bankers, brokers and sales managers. This largely exploratory research process aimed to establish the broad cultural assumptions and practices of a culturally elite social group. Generating an 'atmosphere of place' to define the cultural activity within the City, the project targeted engrained social practices of day-to-day City life as well as exploring the material environment. Drawing on a range of ethnographic material from this study, this chapter is split into two parts. The first engages in detailed ethnographic field-notes, underpinned by an interpretivist philosophy, to present the topographical and material formation of the City of London. Specifically, 
the extraordinary wealth of market action is reproduced within the frame of the City to establish a dominant display of power and privilege. This relates to how the extraordinary wealth generated by the financial services industry is etched into the topographical landscape as a physical manifestation of market dominance. The second part draws on interview data to examine the way in which this institutional and material topography enshrines a distinct symbolic vision of success. Specifically, how competitive market actors seek to internalise the speed, intelligence and discipline of the 'perfect market' in order to strategically advance their own social disposition with the field of finance, reproducing the dominant perception of 'market reality'. Together, what emerges is a cultural market framework that is upheld by those who engage in its processes within the City as the dominant fulcrum of 'truth' and 'virtue'.

Organised around the material landscape of the City of London, strategic action is played out through a competitive struggle of resistance and domination. Here, normative predispositions and cultural inclinations impinge on the bodies and actions of individual agents, resulting in an acquired, individual disposition (Bourdieu, 1973). These processes form the cultural habitus that leads to an 'elective affinity' between agents, enforcing and reproducing an established set of normative cultural assumptions and practices (Bourdieu, 1984). Establishing a unity between the minds, bodies and the market, in the manner of Bourdieu (1996), a self-defined 'intellectual nobility' and 'structural elite' is established that upholds the integrity of the market system through their very thoughts and actions. Moreover, this union forms a "dialectic of consecration and recognition" (Bourdieu, 1977, p. 104) that both selects, and is selected by, a dominant social biography or individual disposition. The framework of the market and the individual become entwined as a cohesive whole, reproducing a durable set of expected values and demands, to engender a long-lasting socially and culturally determined collective of values and experiences. 


\section{The physical construction of an elite space}

To climb the stairs out of Bank tube station is to enter the elite space of financial activity that is the City of London. London's vibrancy and artfulness is instantly left behind, replaced by a world of suited finance workers, brinkmanship and a dominant landscape of market wealth. Opposite the exit to the tube station stands the neo-classical grandeur of the 1930s reconstruction of the Bank of England Building as well as the sixteenth century Royal Exchange building, the historic commercial centre to the City of London and now an exclusive shopping arcade. Up above, the new emerging wealth of the City is symbolically present in the burgeoning towers that stand tall, blocking sky. These constructions, eponymised by Norman Foster's'Gherkin' or Renzo Piano's 'Shard', serve to maintain the City's prominence and, in the case of the latter, mark the City's expansion beyond its traditional geographical boundary. This is a space of enormous wealth and its power is situated for all to see. Towering financial institutions. Tailored suits. Exclusive restaurants. Historical landmarks. This is a space which is made by and operates for the procurement of money. Against a backdrop of ever greater market abstraction and internationalisation in capital flows, the City represents a very human-scale, bounded setting in which the global financial system is rooted and enacted (Cetina \& Bruegger, 2002; MacKenzie, 2009). Within this arena of competition and exchange, the abstractions of the market system become reduced, in a solid and tangible sense, to social, physical and material relations that are played out, in real time, within the institutions and public spaces of the City. At once, the elite dominance of the market mechanism that is so visibly pressed onto the City's topographical landscape becomes internalised in a system "durable, transposable disposition" (Bourdieu, 1990, p. 53). In other words, the very material formation of the City is internalised by the individual agents acting within its parameters to form a distinct and marketable habitus. Focusing on the material landscape of the City, in this manner, deepens a collective understanding of the financial market as an intergenerational statement of power, wealth and ubiquity. 
Specifically, the City of London refers to the historical collection of financial service industries located within a 1.22 square mile that stretches from the Thames at Victoria Embankment, clockwise up through Fleet Street, the Barbican Centre, then to Liverpool Street in the north-east and back down to the Tower of London (Shaxson, 2011). Home to the UK's financial centre, the City is the largest concentration of banking and financial services industries within the UK (ONS, 2012). Along with its tributary, Canary Wharf, the City represents one of the most prominent and near unrivalled cultural and technological centres of market ideology in the world (Kynaston, 2002). In total, it is estimated that the City of London presides over \$1.9tr foreign exchange turnover each day, a figure which accounts for 37 per cent of the global capital flows (City of London, 2013). As a social site, the City explicitly carries within it relations of power to establish a cultural axis of inclusion and exclusion (AbuLughod, 1999; Sack, 1999; 1993). In other words, the material and cultural construction of the City of London provides the limits for possibility. Played out over time, this 'habit forming force' presses on the individual dispositions of market life to organise action, produce practices and construct social structures and worlds (Bourdieu, 1977a; 1984). The very architectural formation of the City is coming together of power, privilege and wealth. The entire topographical landscape is rich of symbolic wealth and the ubiquity of the market mechanism. Filtering down to the occupants who work with the speed and the flow of the market in these spaces, they become, in in Smithsimon's (2010) terms, embodied defenders of this market exclusivity.

The entire architectural and physical construction of the City is defined by the collective wealth and success that the financial services industry generates. The iconic buildings of finance dominate the landscape and stand as physical manifestations of the City's cultural and economic position of power at the heart of the global marketplace. Beneath these bourgeoning structures, their long shadows loom over a tightly knitted collection of lanes and alleys to create an overall enclosed and claustrophobic feeling. The symbolic tapestry of market success, framed by the vast steel and glass 
structures, provides a coherent structure of 'oneness', 'wholeness' and 'greatness' to evoke images of Renaissance cathedrals as well as serve as a very physical reminder of the power and ubiquity of the market mechanism. Their very presence stands as a 'great reservoir of symbolic power' of the market mechanism. Much like the power of the church prior to the Enlightenment, they elicit a dominant and legitimate principle of vision, constructed around a fundamental 'truth' through which an axis of unity is constructed (Wacquant \& Bourdieu, 1993). Rather than the axis of the Church asserting the 'truth' of God, 'truth' is now asserted through the axis of the market institution and the perpetual struggle for efficiency. In the manner of Sack (1999) and Therborn (2013), the symbolic layers of wealth and the material structure of the City is perpetually pressed and shaped to establish this common framework of market truth, justice and morality. As the material manifestation of financial market dominance, the importance of these physical constructions is a reminder that social reality exists not just within the minds of actors, but is also etched onto the material structure of society (Bourdieu, 1980). As individual actors seek to reflect their own dominant position within the field of financial action, a dominant hegemony of success is established that exists between the material and embodied spheres of influence. Coming to impinge on the body, the material organisation of space presents a dominant transmission of knowledge that, as Bourdieu and Passeron (1977) argue, defines success in terms of market engagement. In turn, this, establishing an axis of inclusion that consecrates success in terms of profits and symbolic market wealth, whilst excluding loses in the forms of losses and, ultimately, ejection from the market the market process.

For the City workers who pass through the streets on a daily basis, the scale and grandeur of these buildings are a reminder of who delivers and is responsible for this collective wealth and success. Producing a symbolic hegemony of success, the markers of wealth and power that dominate the landscape come to inform personal inscriptions of status, power and belonging. Impinging on the body, the wearing of designer suits, well-pressed shirts and slick accessories act as a transformative 
rite of passage which is required to legitimately participate in the financial marketplace. As a personal inscription of the body, the material construction of the City enshrines a dominant and legitimising system of capital, organised around projections of power, authority and wealth. Deeply embedded within the physical construction of place exists specific territorial rules that govern the setting and offer constitutive understandings of meaning and practice (Sack, 1993).

These rules, played out over time, are how economic agents each engage with the multiple markets and are structured by the spatial relations and positions people and objects share in the field of finance. This intrinsic tempo of market action produces a legitimised body of knowledge that is implicitly held by all who engage it its processes to be 'true' and 'right'. As a manifestation of belonging and success (not to mention the counterpoint of failure), economic actors engage in a competitive struggle for domination or recognition by reproducing and upholding the sanctity of market action. The market, however, serves to reduce the complexities of social life to monetary gain and, in doing so, becomes its own dispositional logic. Positioned as the dominant structure, the formation of the market removes the costs of economic action from the social consciousness of economic agents, positioning itself as a structuring moral authority. As Thomas, the former CEO and current independent director explains while speaking of his own experiences in turning a struggling bank around:

'What was happening, particularly in some of the trading environments of banks, was that the reward mechanisms got out of control. It became crazy. You had these pot-headed guys running round and they were all focused on making money because that is what their incentives were, and they lost sight of the impact of what they were doing was ... They just got out of control ... you had these obscene scenarios where people were trading companies, asset stripping companies, making vast amount of money along the way and saying, 'That's alright, that is what I was targeted to do, make lots of money'. But look what they did?' 
What Thomas describes is a situation where incentives and reward mechanisms were all about specific targets of making money. With no recourse of action that took in the wider social and economic impact of this, the result was a loss of "sight of the impact of what they were doing" as "pot-headed guys" ran around "focused on making money". Within this statement is the notion of a legitimised and even incentivised myopic focus of the market process of wealth creation - while the economy produced wealth and shareholder value grew, the wider social impact of their actions were accepted. Here, the formation of market action within financial life shaped the aspirations and outcomes of practice by bestowing rewards and recognising the virtues of individual greed and private wealth.

As Thomas highlights, the logic of the market introduces a rationalising discourse that turns the market into a definitive body of knowledge. Surrounded by the dominance and power of the financial market mechanism, a unifying habitus of strategies, constraints and opportunities produces a unifying 'way of being'. In this manner, and drawing on Sack (1999), the material and ideological phenomenon of the financial marketplace comes to impinge on social reality in a dialectic of consecration and recognition, establishing a common framework of truth that enshrines and produces its own situated version of reality. Predominantly, this is an ideology of competition that demands a common affiliation of speed, intelligence and discipline as agents seek to internalise the legitimising capital of financial movement. The physical topology of place within the City serves to highlight the relational and codependent principles of collective unity or differentiation that each relate to integral notions of power and legitimacy of the market mechanism.

The cultural legitimacy of financial market action that is present in the topographical landscape is reflected in the economic agents who uphold its ideology. Suits, watches, handbags, cars, life-style choices all become a personalised display of exclusivity and belonging. Quentin, a metal broker in his late-twenties who has worked in the City for the past five years, explains how the controlling interests 
of financial life play a crucial part in communicating the emblematic power and privilege of the market system:

'I know what it's like, you get caught up in it when you see the guy next to you has got a better watch than you, you need a better watch. It's all competition, everyone is competitive, you want a better car, you want to tell someone that you've just bought a Lamborghini. It's not even the fact that you like driving it, it's the fact that you want other people to know that you have it. It's like a symbolism of success ... you're just thinking about making more money than the next guy, I want to make more money than this guy. It's all about being better, it's all about competition.'

As Quentin explains, the competitive instinct of financial life becomes an inscription on the body, taste and a performative way of being that is played out through the conspicuous consumption of watches, cars and all manner of other accessories that are symbolically displayed in the City; from bags to private schools for their children. The value is not inherent in the car, bag or watch, but as a marker of distinction; so that other people "know that you have it". This is a marker of not just wealth, but market success. These inscriptions of the body all come together to articulate a cultural matrix of financial market interest. Crucially, the symbols display an individual's position within the field of financial action, projecting markers of status, power and belonging. In the way of Bourdieu (1996), the physical manifestations of wealth and status impose upon economic actors, such as Quentin, a present and potential 'situation' in the structure of the distribution of power and capital. Here, the competitive instinct of financial life becomes an inscription on the body, denoting not just status and unity, but serving also as a marker of distinction. Leading to an expected and performative 'way of being', the material and social construction of the field of finance leads to the emergence of a situated and strategic framework of action from which the 'truths' and taken-for-granted assumptions which establish the normative practices of market life can be seen to emerge (Bourdieu, 1984). While, in the first instance, this explicitly concerns the physical shape and design of the City, the spatial formation 
of place can be seen to produce a dominant biography of success. More specifically, this relates to how the extraordinary wealth generated by the financial services industry is etched into the topographical landscape as a physical manifestation of power and privilege to enshrine an exclusive, common attitude amongst its affiliates. As a symbol of power, the rules which govern the field engender a fundamental 'truth' which establishes the dominant and legitimate principal of vision, around which an axis of unity is constructed.

\section{Ideology and Culture: The biography of success}

Existing through the material landscape of the City of London, the financial market system exists as an instrument of both knowledge and communication that, as Bourdieu (1977b) argues, produces a 'logical' and 'moral' system of action and integration. Its spatial and cultural organisation engenders social worlds that impinge on the individual strategic interests to establish a dominant principal of vision, around which an axis of unity is constructed. In this respect, the dominant and legitimate principal vision of the financial marketplace is not just etched onto the topographical landscape, but is pressed onto the bodies and lives through the minds of economic actors who engage in a competitive struggle for domination or recognition. The outcome is a unifying habitus of strategies, constraints and opportunities by reproducing the homologous effects of the social class structure (Bourdieu, 1991). It is at this level of analysis where the market of financial life enters the body and, in Bourdieu's (2011) terms, is transformed into an embodied manifestation of cultural capital. Characterised by a competitive struggle for resources, resistance and domination, the cultural legitimation of capital establishes the set of constraints that govern the setting as well as determine the likelihood of success. Within this, the financial market does not exist as an abstract or ethereal phenomenon but is a construct that is present and brought to life through the consciousness of each individual of financial action. It is through action played out over time, as economic agents each 
engage with the multiple markets, that the intrinsic tempo of the market emerges as a legitimised body of knowledge and is implicitly held by all who engage it its processes to be 'true' and 'right'.

Through a collective engagement of market practice, the external position of the market as a rationalising discourse becomes more tangible, bestowing the rules of the game and establishing a ruling cultural formation. At the heart of the cultural essence of the market is the logic of competition. In an economic sense, this serves to keep prices down and, more importantly, as an incentive for efficiency since it ensures that no one actor has absolute, monopolistic power (Sloman, et al., 2012). However, the performance of competition stands as an ideological construct that serves to purge the financial market of inefficiencies and to establish an inherent 'force' and 'superiority' of capital accumulation. As a 'natural' discourse, competition, in the manner of Bourdieu (1987), guides complex social manoeuvres of interpretation, interest and action. It is an individualising force that serves to dispel the weak and the inferior while rewarding the strong through profits and continued involvement in the game. Buoyed by a marked difference, competition also establishes a high degree of insecurity and vulnerability. Up on the eighth floor of a corporate office block on Fleet Street and speaking to me in the comfortable opulence of the conference suit, Yuri, a senior investment banker for a large American firm, outlines the situation as he sees it:

'I have been doing this [job] for fifteen years ... [and] while I am not unhappy with the job, I know that it doesn't feel right ... It's a very lonely place. You're constantly on alert. It is like you are going through a jungle with like a gun in your hand, you are constantly on alert for, you know, you could get four hundred pages of information to digest incredibly quickly but there is one paragraph in there that could just kill you. And so you are constantly on alert, [thinking] am I processing enough information quickly? You are constantly concerned that about where you are weak relative to others. And then there is your day job as well, right? Am I getting enough business in? Is my business stable? Is my forward looking good? You 
know, what other politics is there and how is that playing out? Am I being a nice person? Have I got time to think about all these things, coping strategies? I am going to get setbacks, how am I going to deal with them? So there is that whole spectrum that I find is more of a physical drain than anything else. So when you finish you are just tired. And it's, it's not so much the work, right? It's the environment, it is an incredibly pressurised environment.'

The visceral sense of loneliness and isolation within Yuri's account is born out of the very competitive nature of financial life. Going through 'the jungle' with a 'gun in your hand', whilst needing to be 'constantly on alert' for that 'one paragraph' that could 'kill you' instils the extent to which competition serves to divide as much as it can unite. Here, market life lives as a game of selfpreservation. This 'unending trial of competition', however, serves to create a 'better' and 'more efficient' system of exchange, driven by a large body of 'rational and informed' profit-maximisers who implicitly adhere to the logic of the market as the principal moral authority. Those who succeed are self-enshrined as a 'separate, sacred group' that ritualises their own exclusivity and adherence to the embedded values of the market (Bourdieu, 1996).

Acting within the spatial framework of the City is to fine tune the necessary skills and hone in on and control the rapid fluctuations of the market in the pursuit of profits. The very experience of financial life demands a common internalisation and embodiment of the speed and the flow of the market itself. Played out on a global scale, agents are pitted against those sitting next to them as well as their counterparts in competing organisations both in the City of London, across New York and beyond. It is a Darwinian game of natural selection, survival, and economic development that demands speed, intelligence and discipline. Through this, an affinity emerges between agents who recognise and reward their sacrificial commitment to the infinite demands of the markets over the limiting demands of the body. Establishing a natural stock of 'difference' and 'superiority', those who are able to internalise the defining features of financial market action are the only ones that thrive. Conversely, 
the 'positive Malthusian check' of market competition works to quickly dispense of those who are unable to either endure or succeed within this cultural framework.

The speed of market action establishes a particular form of high-stakes individual and institutional struggle, characterised by 'ultra-high low' latency engagement with the financial markets. Each institution arms itself with the technological infrastructure that enables individual agents to react and engage in the market mechanism unencumbered by frictions of time. The demand for ever greater speed comes to structure the technological and material landscape in a manner that ensures individual market actors can respond that millisecond faster than anyone else. Accelerating critical market response, every firm is seeking to deliver data, price discovery and trade execution at a rate faster than the next company. On an individual level the demands are such that agents compete to internalise this speed through their everyday actions and engagement in the market mechanism. With a "churn and burn" aspect where traders simply "take stuff down and sell it", financial market action is experienced as a form of intuition, bringing together the institutional environment, technological landscape and the market system. The challenge is not just limited to reacting to the market, but internalising its complexities and managing the visceral struggle of intellectual competition. Again, Yuri's earlier quote establishes a vision of intelligence that, as a system of embodied cultural capital, manifests as a weapon that is used against others for the purposes of exclusion and dominance. As Yuri later recounts:

'You will be in a room and people will be competing to talk about an even more convoluted proposition, layering on, putting on layers and layers of complexity and opening up several thought processes. Effectively it is a challenge to others in the room to keep up.'

Here the challenge laid down to others is an intellectual battle for supremacy and control as well as the punishment of individuals for perceived weakness. It is a form of 'natural selection' that rewards those who are able and 'intellectually endowed', while the weak are exploited for their inability to 
keep up with the financial complexity. Expressed as a resource of power, commitment and capability are transformed into an embodied form of discipline, expressed as a collective acceptance of the necessary constraints and sacrifices entwined with financial life.

To reconcile the vulnerabilities, insecurities and personal sacrifices of market competition, Zaloom (2006, p. 111) argues that economic actors employ what she terms as 'discipline'. As a set of strategies, discipline is used to reconcile the fundamental incompatibility between economic and social life. This is in part employed to mitigate the conflicting costs of engaging in financial hedging and risk, but it also serves to ensure that investments are managed with 'unobstructed' perception. As an idealised state, discipline requires economic actors to acknowledge the market as the only authority; its movements represent financial truth and operate as the definitive moral authority (ibid.). Most commonly, discipline is manifested through the recurring maxim, 'your word is your bond'. With operations running back-to-back and at high speed, once a deal is made it becomes tied up into a matrix of other exchanges and market plays. Going back on your word, in this context, is to undermine the integrity of the market mechanism and to bring the whole system of exchange operations into disrepute. As Robin, a senior broker on the money markets, explains:

'[There are a lot of things that you] just can't do. A lot of it is down to that old fashioned gentlemanly conduct, it fits a purpose. Your word is your bond. When you trade, close a trade, you stand by it. Rule number one ... This is where the military thing factors in. I think the military is very closely in tune with the City because you can't muck about ... You can't have doubt in the line, your good boys know that along the line. There are guys who get it. True to your word. There are people who get that culture ... There is an element of discipline that is extremely important.'

As Robin expresses, the highly pressurised environment of financial life ensures that failing to back your word on a trade or sale is actively punished and weeded out. This construction of discipline is 
seen by Robin to uphold a 'gentlemanly' standard of conduct that rejects practices that fail to uphold the integrity of the market mechanism. Echoing Zaloom (2006), Robin outlines a set of strategies that acknowledge the market as the only authority whilst erecting a spatial boundary of expected behaviour. Within this, the 'doubt' that Robin mentions risks dismantling projections of success or failure by introducing an unpredictability unconnected to the inherent fluctuations of the market mechanism.

This legitimising and sought after system of speed and discipline comes together through a need to experience the speed and the flow of the markets at a corporeal level, absorbing its fluctuating movements and rapid shifts. Felt as an 'innate' response that exists within them, several participants talk of the need to back their 'gut instinct', retain 'courage in their convictions' and, most importantly, be 'pro-active' and 'think on their feet'. An inability to keep up with the pace of the market is an imperfection and this hesitation is there to be exploited. It is, in short, a coming together of mind and body that symbolically reflects the surrounding material and ideological financial marketplace. Situated within an enacted market based reality with its constituent technological and institutional infrastructure, a distinct financial habitus can be seen to impact on the body through the selected choices and actions of economic actors. As Robin goes on to state:

'When you come in [to the City] you might ... not necessarily [be] as sharp as the [next] City bloke, but when you are training as a City guy [you have] got to be sharp. You can't have people, and there are a lot of people who do, namby-pamby around and they get things wrong and it causes car crashes. It is just not good ... In money markets you can't have this nambypamby attitude. People get quick at it and then you get confidence. There is a certain amount of quickness in the City, fast language and conviction. When everyone is smooth and everyone knows and they can trust each other, there are quality individuals and then you get this super- 
subset of individuals that are very, very sharp, very quick, honour each other with a very strong bond.'

The speed of action and sharpness of thought that Robin details serves to combine and establish a close bond of trust and unity. It is a mutually recognisable union organised around market exchange and manifests through 'confidence', 'quickness' and 'conviction'. Within this system of market enactment there is no space for pause or reflection. In the manner of Bourdieu (1977), the framework of the market is seen here to both construct and select an individualised disposition of economic life that is rewarded with a self-defined 'elite status' that serves to separate consecrated 'insiders' from 'commonplace' 'outsiders'. As Robin's statement suggests, when the speed of the market exists through the minds and bodies of economic agents in the field of finance, what emerges is a selfdefined 'super-subset of individuals' who are united by their 'sharpness', 'speed' and collective 'honour'. Bringing together the integrity of the frictionless market experience, this 'super-subset of individuals' establishes, in the words of Bourdieu (1977, p. 104), a "dialectic of consecration and recognition". In other words, the symbolic valuation of market action consecrates those who have embodied and chosen it, in part, because it has chosen them by recognising and rewarding a particular social identity or individual disposition. Thus, the framework of the market and the individual become entwined as a cohesive whole, reproducing the expected values and demands of the field, to engender a socially and culturally determined collective of values and experiences.

\section{Conclusion: A dominant 'way of being'}

Within the boundary of the City of London, the symbolic capital of speed, intelligence and discipline establishes a competitive arena in which economic agents engage in a struggle for distinction. In doing so, competitors contribute to the autonomy and functioning of the field by internalising the symbolic capital of the market system and reifying the product of economic capital. This requires a fundamental and shared doxa amongst the competitors, indicating a shared boundary of 'reality' within which the 
rules of the financial game are seen to be wholly 'true' and fundamentally 'right'. The financial marketplace is characterised by a spatial and symbolic topography of market prominence and success, elite institutional organisations which are the principal producers of economic and symbolic capital bound by a culturally dominant market competition and the rule of profit. In short, this is a cultural frame characterised by the power and ubiquity of the market mechanism as well as the symbolic tapestry of wealth to establish a legitimising framework of market action. Within this established field of financial action, dominant and strategic forms of interested practice are played out by participants in the field in a perpetual battle for legitimation and distinction. The pressures of competitive individualism, shaped by the structural organisation of the market system, serve to dispel the weak and the inferior through the atomised competition of survival, while rewarding the strong through profits and continued involvement in the game. Those who succeed in this game are self-enshrined as a 'separate, sacred group' that ritualise their own exclusivity and adherence to the embedded values of the market (Bourdieu, 1996). As a system of embodied capital, economic agents compete and fine tune their skills to hone in on and control the rapid fluctuations of the market in the pursuit of profits by embodying the dominant values of market action. Within this, an affinity emerges between agents who recognise and reward their 'sacrificial' commitment to the infinite demands of the markets over the limiting demands of the body. As such, there is a shared sense among financial agents of being connected to one another through a collective ability to 'feel the market' as a form of 'rooted essence' to engender an internalised 'way of being'.

Whereas capital, particularly cultural capital, is thought of usually in relation to socially desirable traits (such as intellectual acumen in the university setting or emotional responsiveness in the healthcare system), in the financial field speed, discipline and intelligence each manifest through a prism of individualist competition and survival. In this manner, intelligence is turned into a weapon that is used to exclude, instil vulnerability and exploit other actors in the field in the pursuit of profit. Together, 
speed, discipline and intelligence are a ruling and embodied system of cultural capital through which agents of economic life internalise the speed and the flow of the market system as well as reconcile individual sacrifices or incompatibilities. It is, in this manner, a competitive struggle of dominance and distinction that both focuses the mind as well as enters the body as a constraining set of personal dispositions. As a social relation of power, the legitimate domination of the market order can be seen to directly impinge on these dispositions of financial life to produce a 'logical' and 'moral' social integration of an 'elite' social group who, collectively, feel the speed and the flow of the market through their everyday action. This produces a cultural mechanism of enshrinement in which individuals 'become at one' with the market. Impacting on both the mind and the body, participants of market life reproduce an elite, super sub-set of individuals who are marked by their adherence to economic efficiency and competition. 


\section{Bibliography}

Abu-Lughod, J., 1999. New York, Chicago, Los Angeles: America'a Global Cities. Minneapolis, MN: University of Minnesota Press.

Bourdieu, P., 1973. Cultural Reproduction and Social Reproduction. In: R. Brown, ed. Knowledge, Education and Cultural Change. London: Tavistock, pp. 71-112.

Bourdieu, P., 1977. Outline of a Theory of Practice. Cambridge: Cambridge University Press.

Bourdieu, P., 1980. Questions de Sociologie. Paris: Editions de Minuit.

Bourdieu, P., 1984. Distinction: A Social Critique of the Judgement of Taste. London: Routledge.

Bourdieu, P., 1987. Choses Dittes. Paris: Editions de Minuit.

Bourdieu, P., 1990. The Logic of Practice. Stanford: Stanford University Press.

Bourdieu, P., 1991. Le Champ Littéraire. Actes de la Recherche en Sciences Sociales, 89(September), pp. 4-46.

Bourdieu, P., 1996. The State Nobility: Elite Schools in the Field of Power. Cambridge: Polity Press.

Bourdieu, P., 1998. The Essence of Neoliberalism. [Online]. Le Monde Diplomatique [English Edition], December, p. Available at: http://mondediplo.com/1998/12/08bourdieu [Accessed 10 August 2015.

Bourdieu, P., 2001. Firing Back: Against the Tyranny of the Market 2. London: The New Press.

Bourdieu, P., 2011. The Forms of Capital. In: I. Szeman \& T. Kaposy, eds. Cultural Theory: An Introduction. Chichester: Wiley-Blackwell, pp. 81-93.

Bourdieu, P. \& Passeron, J.-C., 1977. Reproduction in Eduction, Society and Culture. London: SAGE.

Cetina, K. \& Bruegger, U., 2002. Global Microstructures: The Virtual Societies of Financial Markets. American Journal of Sociology, 107(4), pp. 905-950.

Chopra, R., 2003. Neoliberalism as Doxa: Bourdieu's Theory of the State and the Contemporary Indian Discourse on Globalisation and Liberalisation. Cultural Studies, 17(3/4), pp. 419-444.

City of London, 2013. Key Facts. [Online] Available at: http://www.cityoflondon.gov.uk/about-thecity/who-we-are/Pages/key-facts.aspx [Accessed 2509 2013].

Foucault, M., 2010. The Birth of Biopolitics: Lectures at the College de France, 1978-79. Basingstoke, Hants: Palgrave Macmillan.

French, S. \& Leyshon, A., 2010. These F@\#king Guys": The Terrible Waste of a Good Crisis. Environment and Planning, 42(11), pp. 2549-2559.

Kynaston, D., 2002. The City of London Volume IV: A Club No More 1945-2000. London: Pimlico.

MacKenzie, D., 2009. Material Markets: How Economic Agents are Constructed. Oxford: Oxford University Press.

ONS, 2012. Business Register and Employment Survey, s.l.: Office for National Statistics. 
Pauly, L., 2011. The Political Economy of the Financial Crisis. In: J. Ravenhill, ed. Global Political Economy. 3rd ed. Oxford: Oxford University Press, pp. 215-272.

Sack, R., 1993. The Power of Place and Space. Geographical Review, 83(3), pp. 326-329.

Sack, R., 1999. A Sketch of a Geographic Theory of Morality. Annals of the Associations of American Geographers, 89(1), pp. 26-44.

Shaxson, N., 2011. Treasure Islands: Tax Havens and the Men who Stole the World. London: Vintage Books.

Sloman, J., Wride, A. \& Garratt, D., 2012. Economics. 8th ed. Harlow: Pearson Education Limited.

Smithsimon, G., 2010. Inside the Empire: Ethnography of a Global Citadel in New York. Urban Studies, 47(4), pp. 699-724.

Stiglitz, J., 2010. Freefall: Free Markts and the Sinking of the Global Economy. London: Penguin Books.

Swartz, D., 1997. Culture and Power: The Sociology of Pierre Bourdieu. Chicago: University of Chicago Press.

Therborn, G., 2013. "Global Cities", World Power, and the G20 Capital Cities. In: Cities and Crisis: New Critical Urban Theory. London: SAGE, pp. 51-82.

Wacquant, L. \& Bourdieu, P., 1993. From Ruling Class to Field Power: An Interview with Pierre Bourdieu on La noblesse d'Etat. Theory, Culture and Society, 10(3), pp. 19-44.

Zaloom, C., 2006. Out of the Pits: Traders and Technology from Chicago to London. Chigaco: University of Chicago Press. 